\title{
Influence of Silica (SiO2) Loading on the Thermal and Swelling Properties of Hydrogenated-Nitrile-Butadiene-Rubber/Silica (HNBR/Silica) Composites
}

https://doi.org/10.1515/eng-2018-0025

Received July 3, 2016; accepted May 21, 2018

\begin{abstract}
Hydrogenated-Nitrile-Butadiene-Rubber (HNBR) is known for its good physical strength. It is a widely used rubber in electrical insulation and other high performance applications. Performance of HNBR is affected in high temperature and an aggressive fluid environment. Adding silica to HNBR may overcome this problem. In order to investigate the effect of fluids and temperature on $\mathrm{HNBR} /$ silica composites we prepared multiple composites of HNBR with 8.3, 16.7, 33.4, 50 and $66.7 \mathrm{phr}$ of silica $\left(\mathrm{SiO}_{2}\right)$ by two roll compounding method. Swelling index and thermo gravimetric analyses were performed. Calculations of swelling indexes were performed at different time periods with ethanol, toluene and water. For thermo gravimetric analysis (TGA), thermo grams of samples were obtained and \% char yields at $550{ }^{\circ} \mathrm{C}$ were analyzed for all samples. Improvements with the addition of silica were recorded up to a great extent in both analyses. Swelling index decreased with the addition of silica as compared to neat HNBR and reached an optimum position with $50 \mathrm{phr}$ silica loading in ethanol, $8.3 \mathrm{phr}$ in water and $66.7 \mathrm{phr}$ in toluene. Moreover, the HNBR composite with $66.7 \mathrm{phr}$ of silica was found to be the highest thermally stable sample and lost less than $60 \%$ of weight at $550{ }^{\circ} \mathrm{C}$ in comparison to neat HNBR in which $80 \%$ of weight loss occurred at $550{ }^{\circ} \mathrm{C}$.
\end{abstract}

Keywords: HNBR; Composites; Silica; Loading; Filler; Mechanical properties

\footnotetext{
Muhammad Amin: Department of Electrical Engineering, Ghulam Ishaq Khan Institute of Engineering Sciences and Technology, Topi, Pakistan

*Corresponding Author: Abraiz Khattak: Department for Management of Science and Technology Development, Ton Duc Thang University, Ho Chi Minh City, Vietnam

and Faculty of Electrical \& Electronics Engineering, Ton Duc Thang University, Ho Chi Minh City, Vietnam,

E-mail: abraiz.khattak@tdt.edu.vn
}

\section{Introduction}

Hydrogenated-Nitrile-Butadiene-Rubber (HNBR) is a prominent and widely used elastomer [1]. It is obtained by hydrogenation of Nitrile Butadiene Rubber (NBR) $[2,3]$. HNBR is known for sustainability of its physical strength and other properties in exposure to heat, oil and other chemicals [4]. This tough nature of HNBR is provided by its saturated structure and existence of many polar groups. Due to this exceptional nature, it finds usage in many industries e.g. automotive, aerospace and electrical and thermal insulations etc. [5, 6]. Although HNBR is advantageous over NBR in fuel and oil resistance and has also better oxidation and heat resistance than Ethylene-Propylene-Diene-Monomer (EPDM), it decays in high temperature environments and also swells when exposed to solvents $[7,8]$. Thus, the resistance of HNBR needs to be enhanced for applications in high temperature and aggressive solvent environments.

Enhancement in the properties of materials has been an area of research for a long time. Addition of fillers, to the neat materials is an efficient method to enhance their properties [9-12]. Different types of fillers are used to enhance properties of polymers. In order to get optimum results from fillers, some parameters are of great concern during the preparation of composites e.g. mixing time, mixing temperature and modifier content etc. $[12,13]$. Fillers are broadly categorized in two classes, extended fillers and reinforcing fillers [14,15]. Extended fillers are generally used for the extension of formulation e.g. $\mathrm{ATH}, \mathrm{ZnO}$ and ground quartz. Whereas, reinforcing fillers are used for improvement of properties e.g. physical, mechanical and thermal properties. Examples of reinforcing fillers are silica and carbon black etc. Thus, the addition of

Muhammad Ali: University of Engineering and Technology (UET), Taxila, Pakistan 
fillers may result in increased thermal and swelling resistance of overall HNBR composite. Several types of fillers were used previously to improve properties of HNBR [16] e.g. CNT $[17,18]$ ATH [19] and CB [20] etc. However, very limited work has been carried out on the investigation of thermal and swelling properties of HNBR composites [2123] and almost no literature is available on these properties for HNBR/silica composites.

Silica is a reinforcing filler which has good resistivity and thermal stability thus it can bring superior enhancements in the properties of the HNBR. Interaction of silanol group of silica and hydrogen bond in polar HNBR is the reason of improvement in the properties in $\mathrm{HNBR} / \mathrm{SiO}_{2}$ composites [24]. However, further studies are required to find the effect of loading of silica to achieve the utmost thermal properties and swelling behavior of HNBR [25].

Like other fillers, concentration of silica is also an important parameter for the stability of polymer [2628]. Although HNBR has been studied for silica fillers, thermal and swelling properties of $\mathrm{HNBR} / \mathrm{SiO}_{2}$ composites for different concentration of silica has not been reported yet. This is necessary to achieve high performance $\mathrm{HNBR} / \mathrm{SiO}_{2}$ composites.

Keeping in view the importance of thermal stability and swelling behavior for $\mathrm{HNBR} / \mathrm{SiO}_{2}$, we fabricated neat HNBR and its five $\mathrm{HNBR} / \mathrm{SiO}_{2}$ composites with 8.3, 16.7, 33.4, 50 and 66.7 phr of micro silica by two roll compounding as per recommendation of standard ASTM D-3182-07. Later on, all samples were tested for swelling behavior in ethanol, toluene and water. For investigation of thermal properties thermo gravimetric analysis (TGA) was used.

In this work, we have mainly focused on finding the effect of silica loading to achieve enhanced swelling and thermal properties of $\mathrm{HNBR} / \mathrm{SiO}_{2}$ composites.

\section{Materials}

\subsection{Ingredients}

HNBR was procured from Lanxess Chemicals (Germany) and micro-silica $(5 \mu \mathrm{m})$ was obtained from Wuhan Newreach Chemicals (China). Other constituents such as zinc oxide ( $\mathrm{ZnO})$, stearic acid (SA), mercaptobenzothiazole (MBT), sulfur (S), Tetramethyl Thiuram Tetrasulfide (TMTD) and dioctyl phthalate (DOP), Pyrolytic Boron Nitride (PBN) were industrial grade products.

\subsection{Preparation of Composites}

Neat HNBR and its composites were fabricated with different loadings of silica. Two roll compounding method according to ASTM D-3182-07 was used for the preparation of samples [29]. At the start HNBR was masticated and then sulphur, $\mathrm{ZnO}$, stearic acid were added one after other in a sequence as given in Figure 1. The vulcanizates were made in a bolt press machine by curing them at $165^{\circ} \mathrm{C}$ temperature and $10 \mathrm{MPa}$ pressure for 40 minutes. All constituents were mixed in parts per hundreds ratio (phr) as given in Table 1.

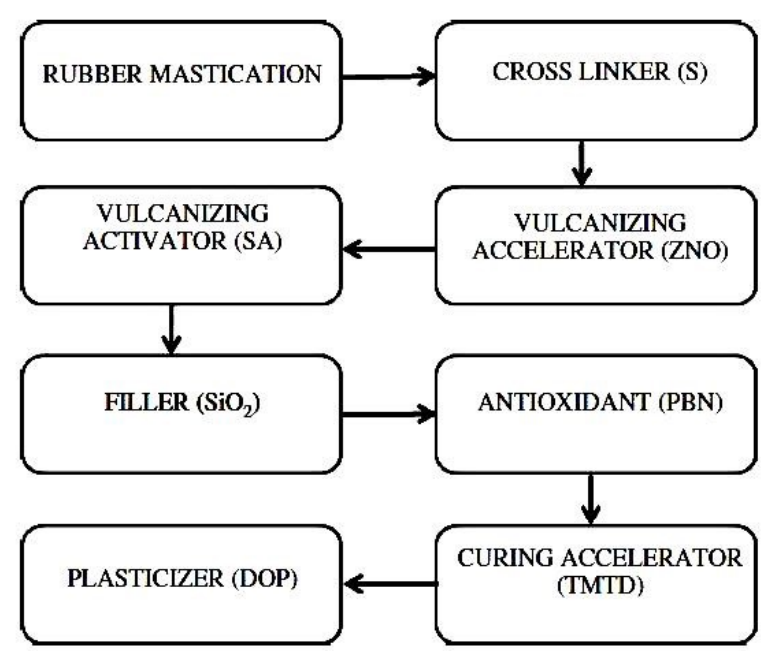

Figure 1: Sequence of constituents' addition in preparation HNBR Composites

\section{Measurements, Instruments and Conditions}

\subsection{Swelling Properties}

All six samples in approximately $1 \mathrm{~cm} \times 1 \mathrm{~cm}$ of area and $2 \mathrm{~mm}$ thickness were used for the measurement of swelling properties [30-34]. Three solvents (water, ethanol and toluene) were used in the experiment. The dry samples' weight $\left(\mathrm{W}_{d}\right)$ was initially recorded by an electronic digital sample having accuracy of $0.001 \mathrm{mg}$. The samples were then dipped in solvent. After a specific amount of time the weight of the swelled samples $\left(\mathrm{W}_{s}\right)$ was recorded. The measurements were also taken for multiple durations to find the effect of dipping time on the swelling of HNBR. 
Table 1: HNBR Composites formulation recipes

\begin{tabular}{|c|c|c|c|c|c|c|c|c|}
\hline \multirow[t]{3}{*}{ S.No. } & \multirow[t]{3}{*}{ Constituent } & \multirow[t]{3}{*}{$A / U$} & $\begin{array}{l}\text { HNBR-0 } \\
\text { Blank }\end{array}$ & $\begin{array}{c}\text { HNBR-1 } \\
\text { HNBR with }\end{array}$ & $\begin{array}{c}\text { HNBR-2 } \\
\text { HNBR with }\end{array}$ & $\begin{array}{c}\text { HNBR-3 } \\
\text { HNBR with }\end{array}$ & $\begin{array}{c}\text { HNBR-4 } \\
\text { HNBR with }\end{array}$ & $\begin{array}{c}\text { HNBR-5 } \\
\text { HNBR with }\end{array}$ \\
\hline & & & (neat) & $8.3 \mathrm{phr}$ & $16.7 \mathrm{phr}$ & 33.4 phr & $50 \mathrm{phr}$ & $66.7 \mathrm{phr}$ \\
\hline & & & HNBR & silica & silica & silica & silica & silica \\
\hline 1 & HNBR & \multirow{9}{*}{ phr } & 100 & 100 & 100 & 100 & 100 & 100 \\
\hline 2 & $S$ & & 1.5 & 1.5 & 1.5 & 1.5 & 1.5 & 1.5 \\
\hline 3 & $\mathrm{ZnO}$ & & 5 & 5 & 5 & 5 & 5 & 5 \\
\hline 4 & SA & & 1 & 1 & 1 & 1 & 1 & 1 \\
\hline 5 & Silica & & 0 & 8.3 & 16.7 & 33.3 & 50 & 66.7 \\
\hline 6 & PBN & & 1 & 0 & 0 & 0 & 0 & 0 \\
\hline 7 & MBTS & & 1 & 1 & 1 & 1 & 1 & 1 \\
\hline 8 & TMTD & & 0.5 & 0.5 & 0.5 & 0.5 & 0.5 & 0.5 \\
\hline 9 & DOP & & 2.5 & 2.5 & 2.5 & 2.5 & 2.5 & 2.5 \\
\hline
\end{tabular}

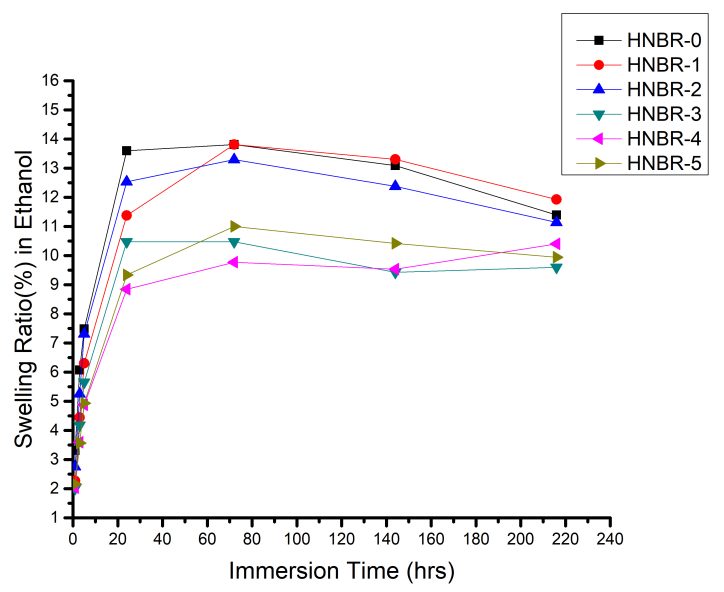

The percentage swelling ratios for neat HNBR and its silica based composites for each solvent were then determined by the following formula [30-34].

$$
\% \text { S.R. }=100 \times\left[\left(\mathrm{W}_{S}-\mathrm{W}_{d}\right) / \mathrm{W}_{d}\right]
$$

(a)

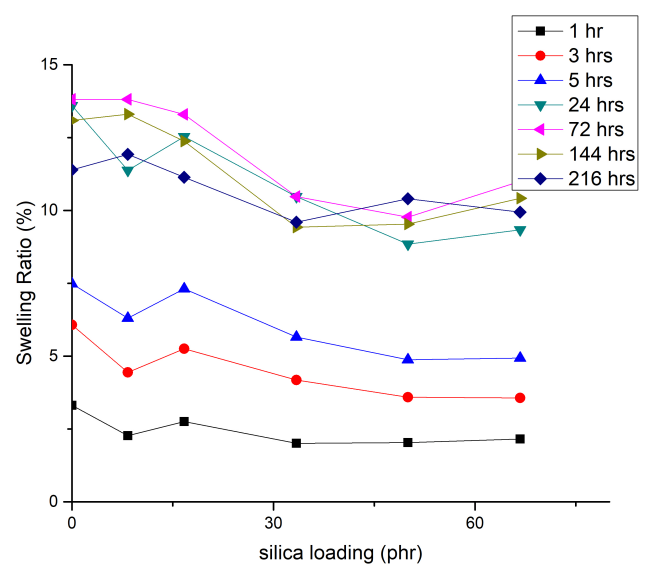

(b)

Figure 2: Swelling behavior of HNBR in ethanol (a) swelling ratio vs. swelling time (b) swelling ratio vs. silica concentration 


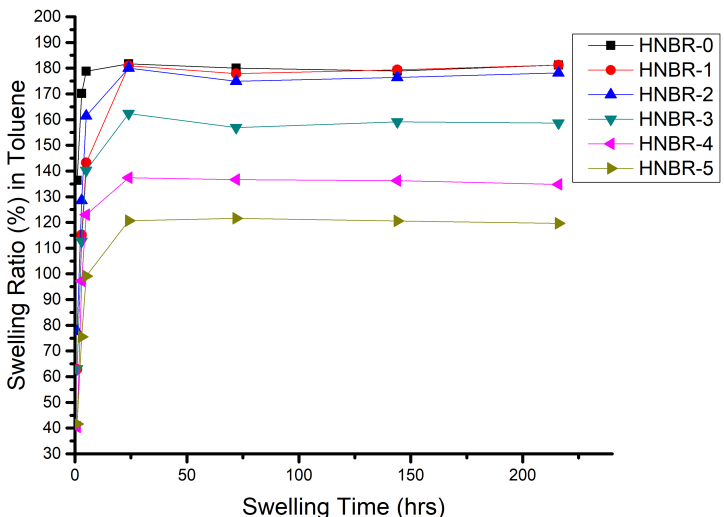

(a)

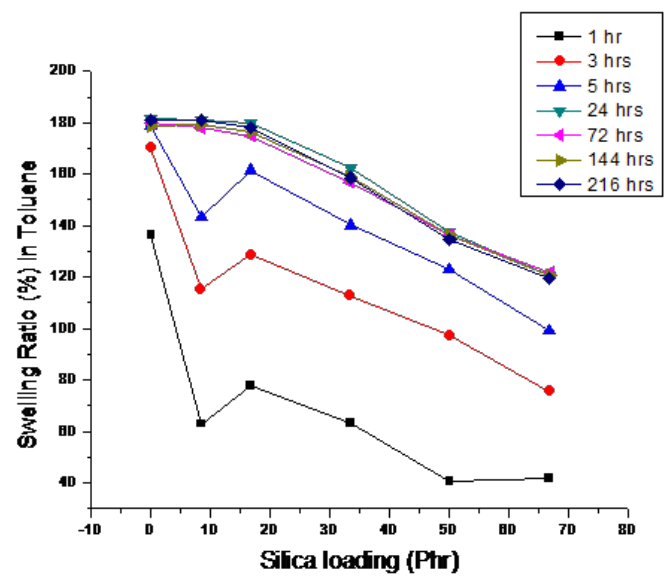

(b)

Figure 3: Swelling behavior of HNBR in toluene (a) swelling ratio vs. swelling time (b) Swelling ratio vs. silica concentration

\section{Thermal Properties}

For measurement of thermal properties Thermo Gravimetric Analysis (TGA) was performed using TGA Q50 (TA instruments, USA) following ASTM E1131 and ISO 11358 standards $[35,36]$. To investigate weight loss by increasing temperature, the temperature was varied from room temperature up to $550{ }^{\circ} \mathrm{C}$ and thermo grams were obtained for the samples. For comparative analysis, temperatures for $10 \%$ weight loss and $50 \%$ weight loss of all samples were recorded. Moreover, the $\%$ char yield was also analyzed for samples at $550{ }^{\circ} \mathrm{C}$.

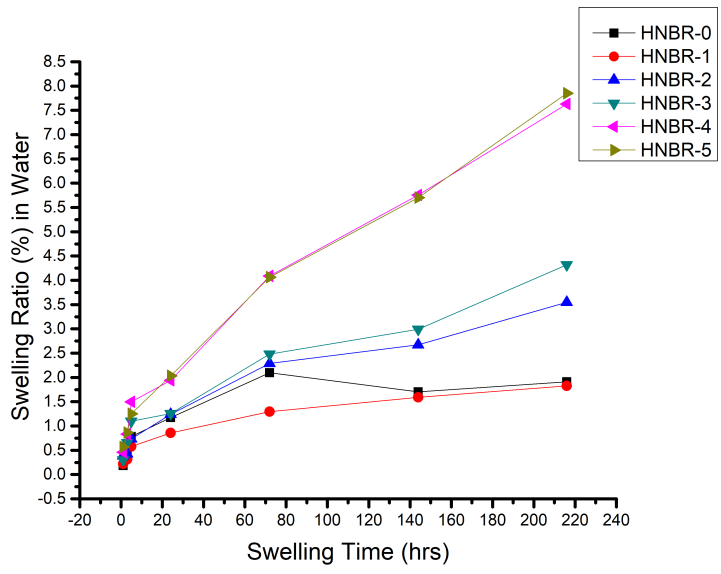

(a)

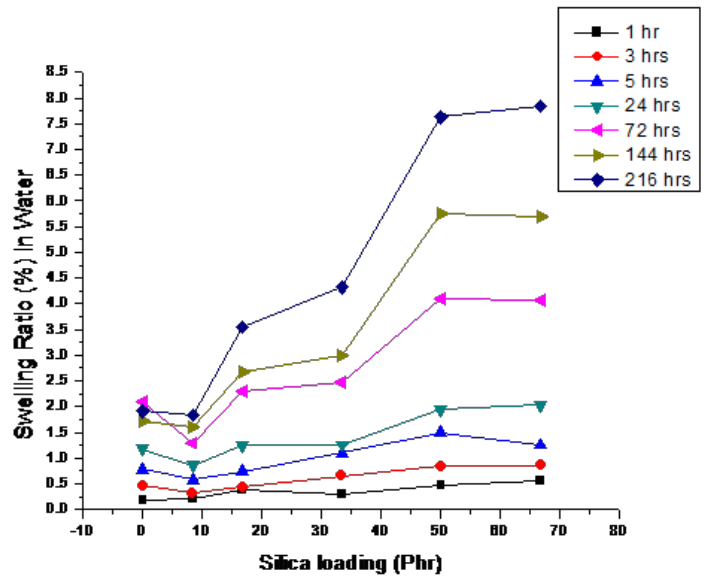

(b)

Figure 4: Swelling behavior of HNBR in water (a) swelling ratio vs. swelling time (b) Swelling ratio vs. silica concentration

\section{Results and Discussions}

\subsection{Analysis of Swelling Behavior}

Measurements for swelling index recorded for each solvent (ethanol, toluene and water) were different. The reason for the different swelling behavior is the exertion of different magnitudes of force from each solvent which depends upon the static fluid pressure of the solvent. Swelling properties of HNBR for ethanol, water and toluene are discussed below.

In ethanol, swelling ratio of HNBR varied with the variation in silica loading.

An increase in swelling ratio with the increase of immersing time in ethanol is clear from Figure 2(a). This increase of swelling ratio is up to a certain value and then de- 

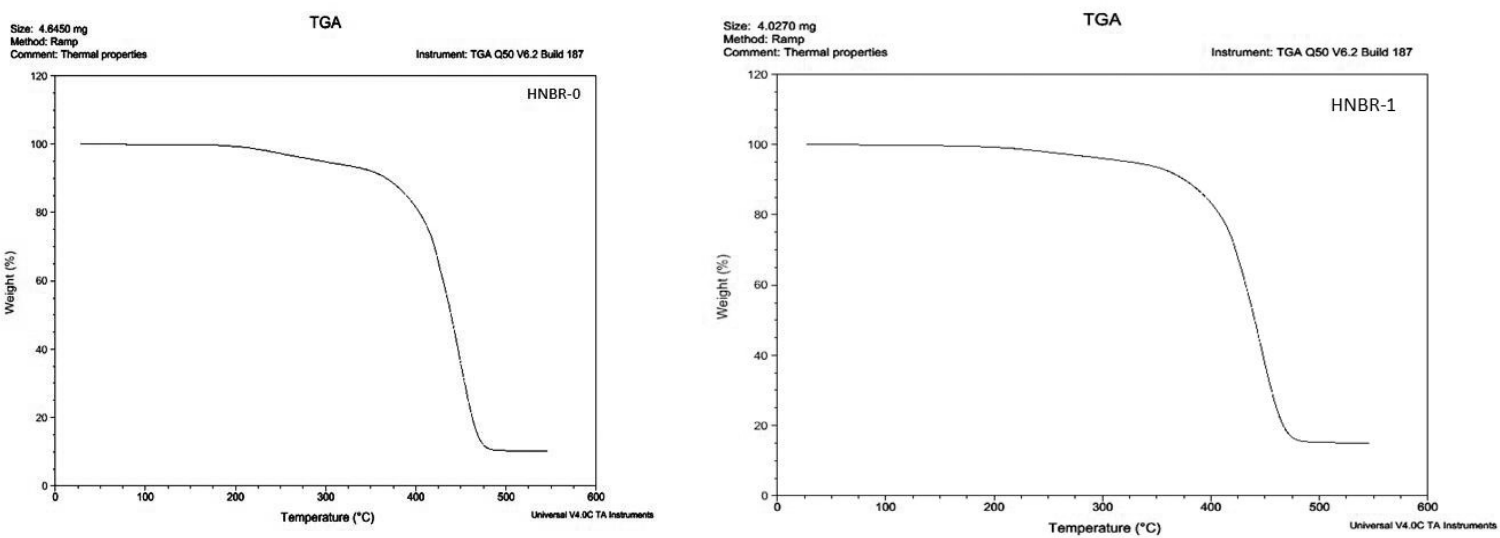

(a) Thermo gram of HNBR-0

(b) Thermo gram of HNBR-1
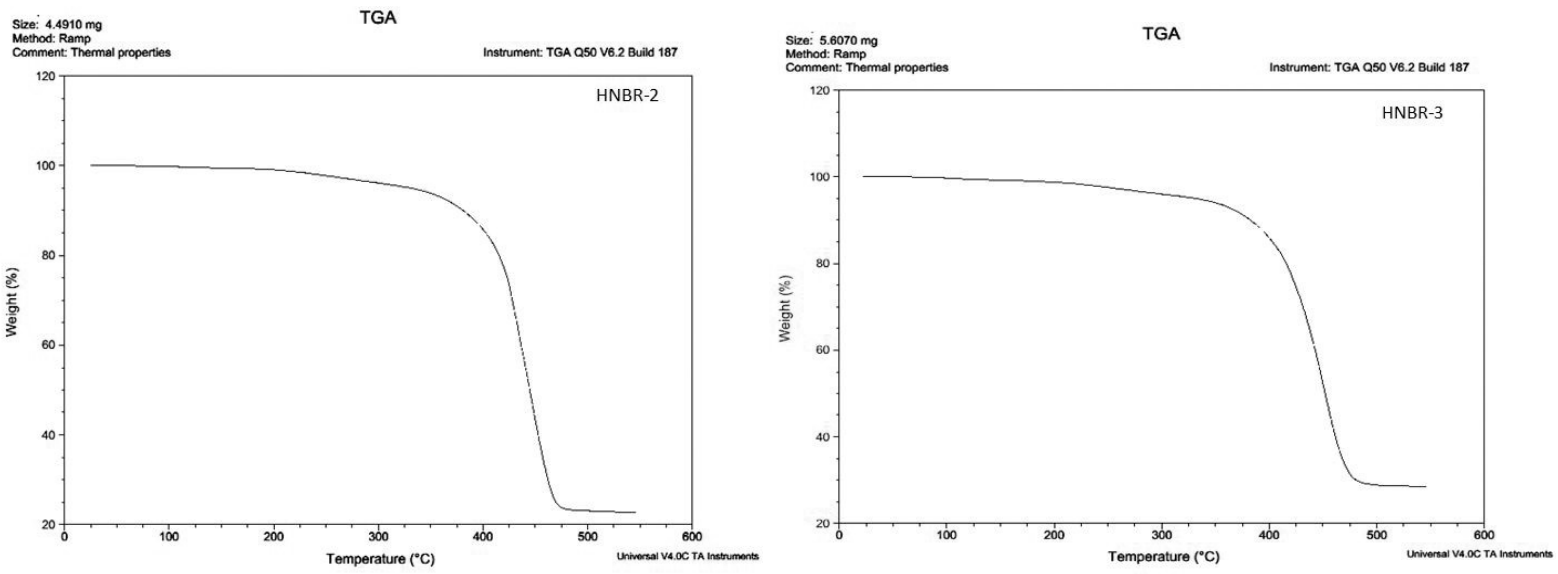

(c) Thermo gram of HNBR-2

(d) Thermo gram of HNBR-3
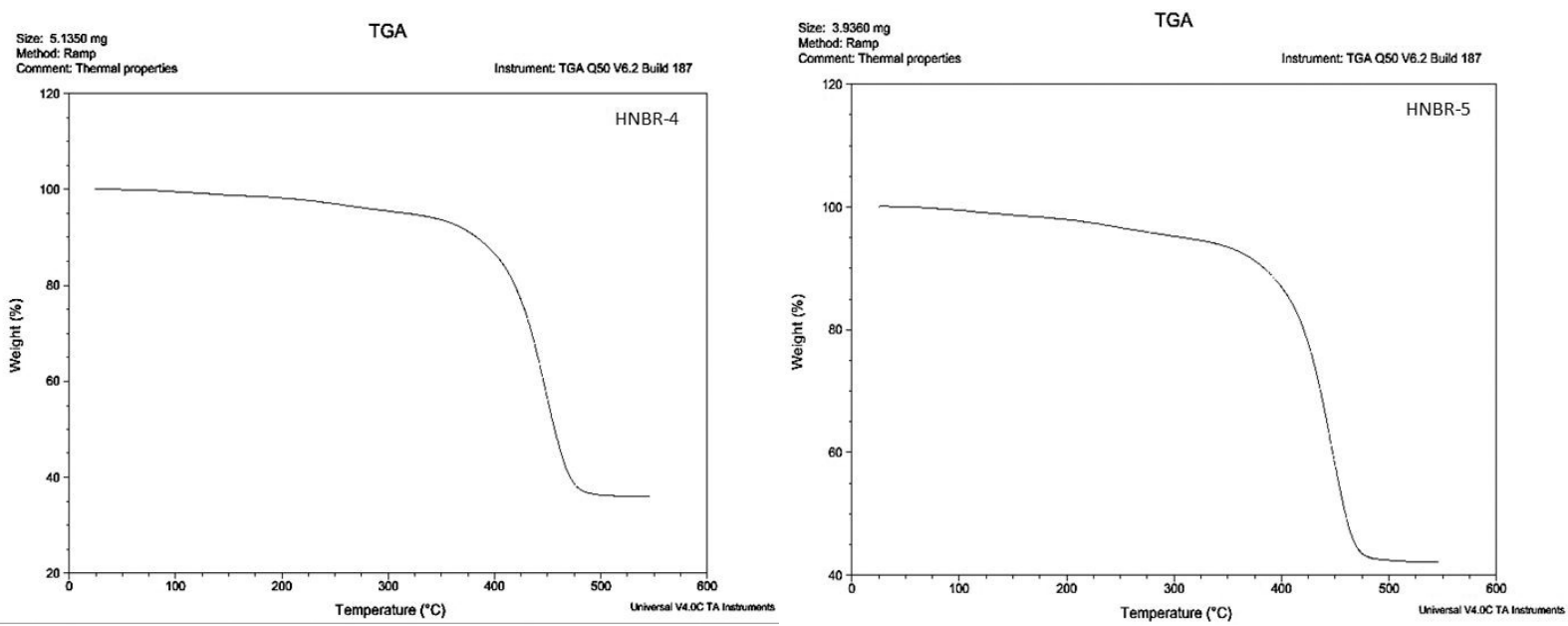

(e) Thermo gram of HNBR-4

(f) Thermo gram of HNBR-5

Figure 5 
creases. The decrease in swelling ratio is due to the dissolving of rubber compound in the ethanol [37, 38]. From Figure 2(b) it is clear that the increase in silica loading results in decrease of swelling ratio. The decrease in swelling ratio of HNBR is due to the force involved between silica particles rubber network. In ethanol HNBR-4 which has $50 \mathrm{phr}$ silica shows better swelling behavior as compared to the other samples up to $140 \mathrm{hrs}$.

Figure 3 shows trend of variation of swelling ratio in toluene vs. immersing time and silica concentration.

In toluene, decrease in swelling ratio was also recorded with the increase of silica loading. Thus, increase of silica resulted in overall compression of the HNBR/silica composite. It also emerged that the swelling ratio of HNBR in toluene was much higher in comparison to ethanol, which reflects higher affinity of HNBR to toluene than ethanol. However, in toluene HNBR-5 with $66.7 \mathrm{phr}$ silica loading showed the best swelling behavior for all time durations, while for ethanol the swelling index reached an optimum point at $50 \mathrm{phr}$ silica loading.

Unexpectedly, the swelling resistance of HNBR was higher in the case of water in comparison to ethanol and toluene.

From Figure 4(a) it is clear that the swelling ratio increases with the increase of immersing time in water. Moreover, it can also be observed that 8.3 phr loading of silica gives a minimum value of the swelling ratio for $\mathrm{HNBR} / \mathrm{SiO}_{2}$ composite. After $8.3 \mathrm{phr}$ loading the swelling ratio continuously increased. This is due to the fact that silica absorbs water, because of the presence of silanol group (Si-OH) in silica which forms a hydrogen bond with water and hence the higher the silica content the higher the swelling of $\mathrm{HNBR} / \mathrm{SiO}_{2}$ composite [39, 40]. However, as shown in Figure 4(b) at 50 phr loading of silica the graph almost becomes a horizontal straight line which means that further loading of silica does not affect the swelling behavior of HNBR. In other words the HNBR reaches its maximum swelling limit.

\subsection{Thermo Gravimetric Analysis (TGA)}

In order to analyze thermal stability of each formulation its individual thermo gram was obtained which are given in Figure 5(a-e). The loss of weight was faster in the case of HNBR-0 while it was observed that the length of the slope of weight loss curve increased as function of silica loading. At the end of experiment at $550{ }^{\circ} \mathrm{C}$ the HNBR-0 lost almost $80 \%$ of its weight while HNBR-5 with $66.7 \mathrm{phr}$ silica lost almost less than $60 \%$ which is evident of improved of thermal stability through addition of silica.
From Figure 6 it is clear that sample HNBR-5 is more stable in comparison with other samples and hence gave highest value $383.84^{\circ} \mathrm{C}$ for $10 \%$ loss in weight. The same trend was followed when the temperature was increased and HNBR- 5 was stable in comparison to other samples by having 50\% loss in weight at the highest temperature of $459.23^{\circ} \mathrm{C}$. From Figure 6 it is also clear that by increasing the concentration of silica the thermal stability of rubber increases which is due to the internal strong $\mathrm{Si}-\mathrm{O}$ bonding in $\mathrm{SiO}_{2}$ as well as firm interaction of silanol group of silica with polymer network.

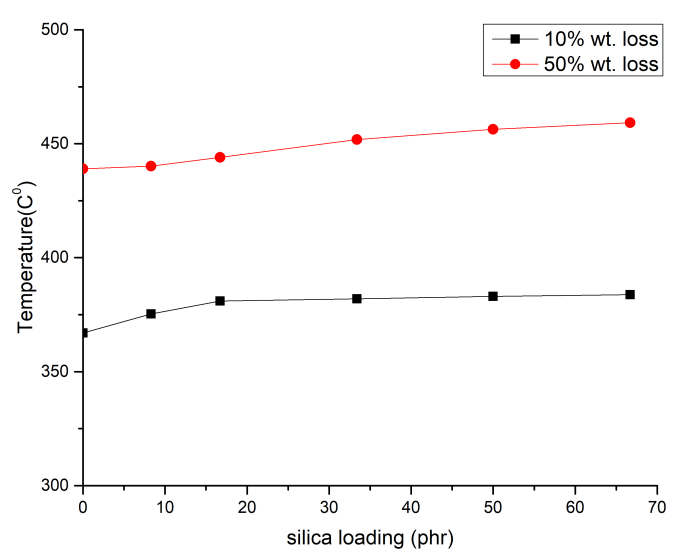

Figure 6: Temperature at $10 \%$ and $50 \%$ wt. loss with respect silica concentration

Neat sample (HNBR-0) gave the smallest char yield which was approximately $10 \%$ of initial weight of the sample, whereas HNBR- 5 gave the highest char yield which is $42.12 \%$ of the initial weight of the sample as shown in Figure 7. From Figure 7 it is also clear the char yield increased with the increase of silica loading.

\section{Conclusions}

Multiple $\mathrm{HNBR} / \mathrm{SiO}_{2}$ composites were prepared with different loadings of silica and tested for swelling behavior and thermal properties. Silica improved the swelling and thermal properties of HNBR but deteriorated in water. Composite with $8.3 \mathrm{phr}$ silica was found with the best swelling behavior in water and for ethanol and toluene the optimum loadings of silica were $50 \mathrm{phr}$ and $66.7 \mathrm{phr}$ respectively. From TGA it emerged that composite with 66.7 phr of silica was more thermally stable and showed loss of weight less than $60 \%$ at $550^{\circ} \mathrm{C}$, which was less in compari- 


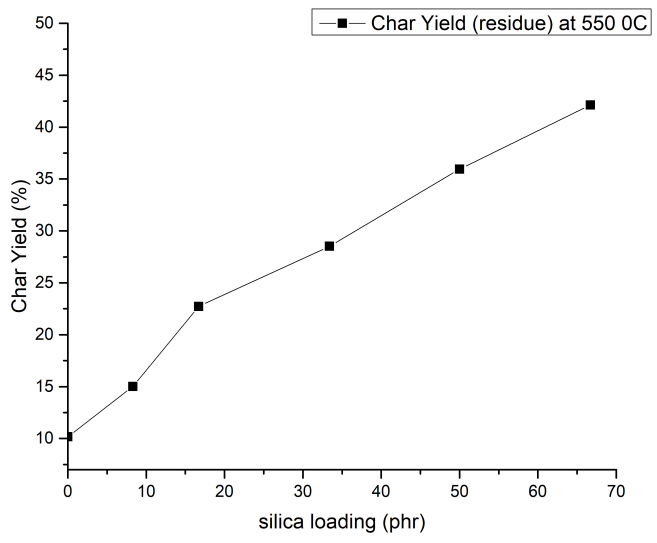

Figure 7: Char Yield at $550^{\circ} \mathrm{C}$ versus silica concentration

son with other samples. Thermo grams obtained from TGA also showed that by increasing silica loading the weight loss in $\mathrm{HNBR} / \mathrm{SiO}_{2}$ was decreased.

\section{References}

[1] Agnelli, S., G. Ramorino, S. Passera, J. Karger-Kocsis, and T. Riccò. "Fracture resistance of rubbers with MWCNT, organoclay, silica and carbon black fillers as assessed by the J-integral: effects of rubber type and filler concentration." Express Polymer Letters 6, no. 7 (2012): 581-587.

[2] Perraud, Sophie, Marie-France Vallat, Marie-Odile David, and Jerzy Kuczynski. "Network characteristics of hydrogenated nitrile butadiene rubber networks obtained by radiation crosslinking by electron beam." Polymer Degradation and Stability 95, no. 9 (2010): 1495-1501.

[3] Marshall, A. J., I. R. Jobe, T. Dee, and C. Taylor. "Determination of the degree of hydrogenation in hydrogenated nitrile-butadiene rubber (HNBR)." Rubber chemistry and technology 63, no. 2 (1990): 244-255.

[4] Madhuranthakam, Chandra Mouli R., Qinmin Pan, and Garry L. Rempel. "Continuous process for production of hydrogenated nitrile butadiene rubber using a Kenics ${ }^{\circledR} \mathrm{KMX}$ static mixer reactor." AlChE journal 55, no. 11 (2009): 2934-2944.

[5] Minglei, Zhang Chunmei Du Huatai Pang, and Zhou Yi. "Influence of Different Fillers on Performance of HNBR Ablative Materials [J]." Aerospace Materials \& Technology 6 (2010): 015.

[6] Wang, Xunzhang, Liqun Zhang, Yang Han, Xiangke Shi, Weimin Wang, and Dongmei Yue. "New method for hydrogenating NBR latex." Journal of Applied Polymer Science 127, no. 6 (2013): 4764-4768.

[7] Hashimoto, K., N. Watanabe, M. Oyama, and Y. Todani. "127th ACS Rubber Division Meeting." Los Angeles, California (24 April 1985) (1985).

[8] Cai, Wei-ting, Li-qun Zhang, and Ming TIAN. "Study on the properties of HNBR composites reinforced by silicate nano-short fiber." China Rubber Industry 54, no. 12 (2007): 709.
[9] Chen, Shuguo, Haiyang Yu, Wentan Ren, and Yong Zhang. "Thermal degradation behavior of hydrogenated nitrile-butadiene rubber (HNBR)/clay nanocomposite and HNBR/clay/carbon nanotubes nanocomposites." Thermochimica Acta 491, no. 1 (2009): 103-108.

[10] Kalachandra, S. "Influence of fillers on the water absorption of composites." Dental Materials 5, no. 4 (1989): 283-288.

[11] Gårdebjer, Sofie, Anna Bergstrand, Alexander Idström, Camilla Börstell, Stefan Naana, Lars Nordstierna, and Anette Larsson. "Solid-state NMR to quantify surface coverage and chain length of lactic acid modified cellulose nanocrystals, used as fillers in biodegradable composites." Composites Science and Technology 107 (2015): 1-9.

[12] Wypych, George. Handbook of fillers. ChemTec Pub., 2010.

[13] Cai, Wei-ting, Li-qun Zhang, and Ming TIAN. "Study on the properties of HNBR composites reinforced by silicate nano-short fiber." China Rubber Industry 54, no. 12 (2007): 709.

[14] Guth, Eugene. "Theory of filler reinforcement." Journal of applied physics 16, no. 1 (1945): 20-25.

[15] Kashiwagi, Takashi, Fangming Du, Jack F. Douglas, Karen I. Winey, Richard H. Harris, and John R. Shields. "Nanoparticle networks reduce the flammability of polymer nanocomposites." Nature materials 4, no. 12 (2005): 928-933.

[16] Guan, Yue, Ling-Xin Zhang, Li-Qun Zhang, and Yong-Lai Lu. "Study on ablative properties and mechanisms of hydrogenated nitrile butadiene rubber (HNBR) composites containing different fillers." Polymer Degradation and Stability 96, no. 5 (2011): 808-817.

[17] Wu, Wenjing, Yinghao Zhai, Yong Zhang, and Wentan Ren. "Mechanical and microwave absorbing properties of $<\mathrm{i}>$ in situ $</ i>$ prepared hydrogenated acrylonitrile-butadiene rubber/rare earth acrylate composites." Composites Part B: Engineering 56 (2014): 497-503.

[18] Yue, Dongmei, Yunfang Liu, Zengmin Shen, and Liqun Zhang. "Study on preparation and properties of carbon nanotubes/rubber composites." Journal of materials science 41, no. 8 (2006): 2541-2544.

[19] Wang, He, Xinyan Shi, and Shugao Zhao. "Effects of Magnesium Hydroxide on the Flame Retardancy of Ethylene-Vinyl Acetate Copolymers/Nitrile Rubber Blends." Journal of Macromolecular Science, Part B 53, no. 5 (2014): 769-780.

[20] Zhao, Xingbo, Qiuyu Zhang, Junwei Gu, Dezhong Yin, and Changjie Yin. "Effects of Carbon Black on the Properties of HNBR Reinforced by in-situ Prepared ZDMA." Polymer-Plastics Technology and Engineering 50, no. 15 (2011): 1507-1510.

[21] Promchim, Jantaraporn, Sirichai Kanking, Piyaporn Niltui, Ekachai Wimolmala, and Narongrit Sombatsompop. "Swelling and mechanical properties of (acrylonitrile-butadiene rubber)/(hydrogenated acrylonitrile-butadiene rubber) blends with precipitated silica filled in gasohol fuels." Journal of Vinyl and Additive Technology (2014).

[22] Facio, Adali Castañeda, Aide Saenz Galindo, Lorena Farias Cepeda, Lluvia López López, and Ramón Díaz de León-Gómez. "Thermal Degradation of Synthetic Rubber Nanocomposites." In Thermal Degradation of Polymer Blends, Composites and Nanocomposites, pp. 157-191. Springer International Publishing, 2015.

[23] Nasreddine, Victor, and Matthias Soddemann. "HNBR compositions with very high filler levels having excellent processability and resistance to aggressive fluids." U.S. Patent 9,023,936, is- 
sued May 5, 2015.

[24] Nillawong, Manuchet, Pongdhorn Sae-Oui, and Chakrit Sirisinha. "Influences of Coagent Hybrid Ratios and Silanes on Viscoelastic Properties of Silica-Filled HNBR." Advanced Materials Research 747 (2013): 564-567.

[25] Tangudom, Paveena, Sirinthorn Thongsang, and Narongrit Sombatsompop. "Cure and mechanical properties and abrasive wear behavior of natural rubber, styrene-butadiene rubber and their blends reinforced with silica hybrid fillers."Materials \& Design 53 (2014): 856-864.

[26] Arrighi, V., I. J. McEwen, H. Qian, and MB Serrano Prieto. "The glass transition and interfacial layer in styrene-butadiene rubber containing silica nanofiller."Polymer 44, no. 20 (2003): 6259-6266.

[27] Javni, I., W. Zhang, V. Karajkov, Z. S. Petrovic, and V. Divjakovic. "Effect of nano-and micro-silica fillers on polyurethane foam properties." Journal of cellular plastics 38, no. 3 (2002): 229 239.

[28] Pustak, Anđela, Matjaž Denac, Mirela Leskovac, Iztok Švab, Vojko Musil, and Ivan Šmit. "Polypropylene/silica micro-and nanocomposites modified with poly (styrene-b-ethylene-cobutylene-b-styrene)." Journal of Applied Polymer Science132, no. 6 (2015).

[29] ASTM D3182-07 (2012), Standard Practice for RubberMaterials, Equipment, and Procedures for Mixing Standard Compounds and Preparing Standard Vulcanized Sheets, ASTM International, West Conshohocken, PA, 2012

[30] ASTM D3616-95 (2014), Standard Test Method for RubberDetermination of Gel, Swelling Index, and Dilute Solution Viscosity, ASTM International, West Conshohocken, PA, 2014

[31] Cadambi, Rahul M., and Elaheh Ghassemieh. "The ageing behaviour of hydrogenated nitrile butadiene rubber/nanoclay nanocomposites in various mediums." Journal of Elastomers and Plastics (2012): 0095244311429736.
[32] Mathew, Lovely, K. U. Joseph, and Rani Joseph. "Swelling behaviour of isora/natural rubber composites in oils used in automobiles." Bulletin of Materials Science 29, no. 1 (2006): 91-99.

[33] Salmah, H., B. N. Azra, M. D. Yusrina, and H. Ismail. "A comparative study of polypropylene/(chloroprene rubber) and (recycled polypropylene)/(chloroprene rubber) blends." Journal of Vinyl and Additive Technology 21, no. 2 (2015): 122-127.

[34] Wei, Dongya, Ning He, Jing Zhao, and Zhaobo Wang. "Mechanical, Water-Swelling, and Morphological Properties of WaterSwellable Thermoplastic Vulcanizates Based on High Density Polyethylene/Chlorinated Polyethylene/Nitrile Butadiene Rubber/Cross-Linked Sodium Polyacrylate Blends." PolymerPlastics Technology and Engineering 54, no. 6 (2015): 616-624.

[35] ASTM E1131-08 (2014), Standard Test Method for Compositional Analysis by Thermogravimetry, ASTM International, West Conshohocken, PA, 2014

[36] ISO 11358-1:2014, Plastics - Thermogravimetry (TG) of polymers

[37] Berahman, R., Raiati, M., Mazidi, M. M., \& Paran, S. M. R. (2016). Preparation and characterization of vulcanized silicone rubber/halloysite nanotube nanocomposites: Effect of matrix hardness and HNT content. Materials \& Design, 104, 333-345.

[38] Liu, G., Hoch, M., Liu, S., Kulbaba, K., \& Qiu, G. (2015). Quantitative exploration of the swelling response for carbon black filled hydrogenated nitrile rubber with three-dimensional solubility parameters. Polymer Bulletin, 72(8), 1961-1974.

[39] Carr, P. W., Dolan, J. W., Dorsey, J. G., Snyder, L. R., \& Kirkland, J. J. (2015). Contributions to reversed-phase column selectivity: III. Column hydrogen-bond basicity. Journal of Chromatography A, 1395, 57-64.

[40] Lee, D., Ahn, G., \& Ryu, S. (2014). Two-dimensional water diffusion at a graphene-silica interface. Journal of the American Chemical Society, 136(18), 6634-6642. 